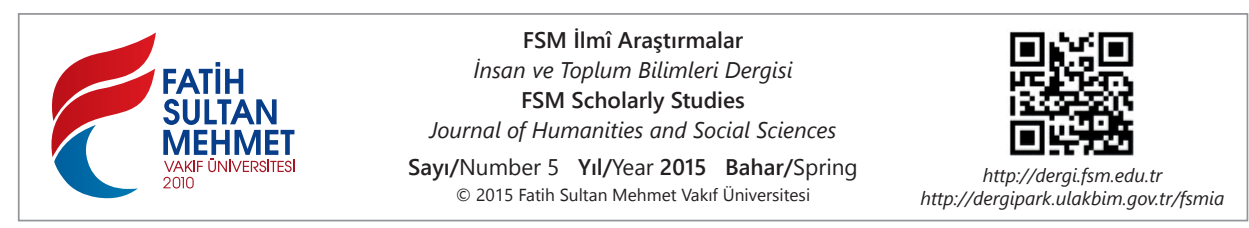

\title{
Dönüşümcü ve İşlemci Liderlik Stilleri: Kavramsal Çerçevesi ve Eğitim Örgütleri Açısından Etkileri
}

\begin{abstract}
Ahmet Avcl*
\section{Özet}

Örgütlerin iç ve dış çevrelerinde yaşanan hızlı gelişmeler, daha etkin ve etkili liderlik tarzlarının organizasyonlarda uygulanmasını zorunlu kılmıştır. Dönüşümcü ve işlemci liderlik stillerinin, örgütlerin yapılarına, kültürlerine ve başarılarına ayrı ayrı etkileri bulunmaktadır. Bu durum, eğitim örgütleri için de aynıdır. İşlemci liderler, örgütün önceden gelen işleyiş sistemine pek müdahale etmezken; dönüşümcü liderler, bilimsel veriler ve teknolojik gelişmeler ışığında örgütün değişim ve dönüşümünü sağlarlar. Dönüşümcü liderlik; okullardaki başarının ve kaliteli eğitim ve öğretimin temel belirleyicilerinden biridir. Dönüşümcü okul müdürleri; öğretmenler başta olmak üzere okuldaki tüm çalışanlarla birlik ve beraberlik içinde hareket eder, okulun hedeflerinin gerçekleştirilmesi konusunda vizyoner ve karizmatik kişilikleriyle öğretmenlere rol-model olur; teknolojiyi ve bilimsel gelişmeleri takip ederek okullarını bu veriler çerçevesinde değiştirir ve geliştirir. Bu tespitlerden hareketle, makalenin temel amac1; dönüşümcü ve işlemci liderliğin genel bir kavramsal çerçevesini sunmak; yapıları ve alt boyutları hakkında bilgi vermek; kişisel ve örgütsel açıdan etkilerini belirtmek; eğitim örgütleri açısından bazı çıkarımlarda ve önerilerde bulunmaktır.
\end{abstract}

Anahtar Kelimeler: Dönüşümcü liderlik, işlemci liderlik, eğitim örgütleri, örgüt kültürü.

\section{Transformational and Transactional Leadership Styles: Conceptual Framework and Their Effects on Educational Organizations}

\section{Abstract}

Rapid developments in internal and external environments of organizations oblige implementation of more active and effective leadership styles in organizations. There are seperately effects of transformational and transactional leadership styles to the organization structures, cultures and successes. That situation is same for educational organizations too. While transactional leaders do not interfere to the organization's foregoer running system much, transformational leaders provide the organization's change and transfor-

* Yrd. Doç. Dr., Fatih Sultan Mehmet Vakıf Üniversitesi Eğitim Bilimleri Bölümü, Sürekli Eğitim Uygulama ve Araştırma Merkezi Müdürü \& Kariyer, Girişimcilik ve Mesleki Test Merkezi Müdürü, İstanbul/Türkiye, aavci@fsm.edu.tr 
mation in the light of scientific data and technological developments. Transformational leadership is one of basic determinants of success and quality education in schools. Transformational headteachers move in unity particularly with teachers and all employees, become role model for teachers with their visionary and charismatic personalities in subject of realization of the school aims, follow technology and scientific developments, change and improve their schools as part of those data. With reference to those evaluation, the aim of this article is to present general conceptual framework of transformational and transactional leaderships, inform about their structures and sub-dimensions, state their effects in terms of personal and organizational, make some suggestions and inference in terms of the educational organizations.

Keywords: Transformational leadership, transactional leadership, educational organizations, organization culture. 


\section{Giriş}

Kendini iyi tanıyan, imkan ve kabiliyetlerinin farkında olarak kapasitesini en verimli şekilde kullanabilen, sağlam bir karakter yapısına sahip, yenilikçi ve girişimci, lider ruhlu bireylerin yetiştirilmesi, artık günümüzün önemli meselelerinden biridir. Günümüzde yaşanan rekabet koşulları, her alanda liderliği çok daha önemli hale getirmiştir. Örgütlerin iç ve diş çevrelerinde yaşanan hızlı gelişmeler, daha etkin ve etkili liderlik tarzlarının organizasyonlarda uygulanmasını zorunlu kılmıştır. ${ }^{1}$ Tüm kurumların işleyişinde olduğu gibi eğitim kurumlarının da başar1l1, verimli, yenilikçi ve girişimci; toplumun ihtiyaç ve sorunlarına duyarlı; zamanın şartlarına göre kendini yenileyebilen; öğretmenler başta olmak üzere tüm çalışanlarıyla aynı hedefe doğru ekip olarak ve takım ruhuyla koşan ${ }^{2}$ kurumunun hedeflerini gerçekleştirebilmek için beklenilenin ötesinde motive olmuş bireyleri organize edebilen bir anlayışın oluşabilmesinde; karizmatik, bilgili, erdemli, vizyoner, girişimci, ilkeli ve çalışkan müdürlerin-yöneticilerin varlığı hayati derecede önemlidir. ${ }^{3}$ Sağlıklı okul iklimini oluşturarak; öğrencilerin bireysel farklılıklarının dikkate alındığı, imkan ve kabiliyetlerinin geliştirilmesi için çaba sarf edildiği, akademik ve kişisel başarıları yüksek öğrencilerin yetiştirildiği bir okul kültürünün oluşturulmasında ve aynı zamanda çalışanların örgütsel vatandaşlık davranışları sergilediği bir çalışma atmosferinin hazırlanmasında dönüşümcü liderlik tarzını benimseyen okul müdürlerine ihtiyaç duyulduğunu ortaya koyan birçok araştırma mevcuttur. ${ }^{4}$

1 J. M. Burns, Leadership, New York: Harper and Row, Publishers, Inc., 1978; B. M. Bass, The Bass Handbook of Leadership, Theory, Research, and Managerial Applications, New York: Free Press, 2008; G. Yukl, Managerial leadership: A review of theory and research, Journal of Management, 15(2), 1989, s. 251-289; P. F. Drucker, The coming of the new organization, Harvard Business Review, January-February, 28, 1988, s. 45-53; J. P. Kotter, What leaders really do? Harvard Business Review, 79(11), 2001, s. 85-96.

2 K. Leithwood, \& D. Jantzi, Transformational school leadership for large-scale reform: Effects on students, teachers, and their classroom practices, School Effectiveness and School Improvement, 17(2), 2006, s. 201-227; K. Barnett, J. McCormick, \& R.Conners, Transformastional leadership in schools - Panacea, placebo or problem? Journal of Educational Administration, 39(1), 1999, s. 24-46.

3 K. Leithwood, The move toward transformational leadership, Educational Leadership, 49(5), 1992, s. 8-12; R. Bogler, The influence of leadership style on teacher job satisfaction, Educational Administration Quarterly, 37(5), 2001, s. 662-683.

4 D. G. Pounder, R. T. Ogawa \& E.A. Adams, Leadership as an organization - wide phenomena: Its impact on school performance, Educational Administration Ouarterly, 31(4), 1995, s. 564588; K. Leithwood, \& D. Jantzi, Transformational school leadership for large-scale reform: Effects on students, teachers, and their classroom practices, School Effectiveness and School Improvement, 17(2), 2006, s. 201-227; F. Geijsel, P. Sleegers, K. Leithwood, \& D. Jantzi, Transformational leadership effects on teachers' commitment and effort toward school reform, Journal of Educational Administration, 41(3), 2002, s. 228-256; Bogler, a.g.e., s. 662-683; M. DiPaola, \& M.Tschannen-Moran, Organizational citizenship behavior in schools and its relationship to school climate, Journal of School Leadership, 11(5), 2001, s. 424-447; M. F. DiPaola, \& W. K. Hoy, Organizational citizenship of faculty and achievement of high school students, The High School Journal, 88(3), 2005, s. 35-44. 
Düşünceler, stratejiler ve inançlar sürekli olarak değişmektedir. Okul müdürleri, değişen toplum yapısına uyum sağlamak zorundadır. Toplumun beklentilerini karşılamayan bir okulun etkili ve başarılı olabilmesi asla mümkün değildir. ${ }^{5}$ Bu bağlamda, yönetim ve liderler en küçüğünden en büyüğüne tüm kurumların vazgeçilmez ihtiyaçlarıdır. Onlar, kurumu bir arada tutan, verimli çalışmasını sağlayan ve kurumsal başarının gerçekleşmesini temin eden en önemli öğelerdir. ${ }^{6}$ Liderler, özel ve kamu sektörünün tüm kurum ve kuruluşlarının başarısında, sürdürülebilir gelişimlerinde, örgüt kültürünün oluşturulması ve istikrarlı bir biçimde devam ettirilmesinde en önemli etkiye sahip kişilerdir. ${ }^{7} \mathrm{Bu}$ durum, eğitim örgütleri için de aynen geçerlidir. Nitekim Hoy ve Miskel'e göre, ${ }^{8}$ eğitimin içinden veya dışından birçok kişi ve kurumun, okullardan her geçen gün artan beklentileri, eğitimde liderliğin önemini artıran en önemli öğe olarak görülmektedir. Bu noktada, yönetim ve liderlik rolü, okul müdürü için çok kritik bir öneme sahiptir ve belki de okul müdürünün en önemli özelliğini oluşturmaktadır. ${ }^{9}$ Bass'a göre liderlik, örgütteki başarı ya da başarısızlığın tek ve en önemli etkeni olarak kabul edilir. ${ }^{10}$ Birçok araştırmacıya göre bu durum, eğitim örgütlerindeki liderler yani okul müdürleri için de geçerlidir. Okul müdürleri okulun başarılı yönetilmesinden, eğitim ve öğretimin verimli olmasından birinci derecede sorumludur. ${ }^{11} \mathrm{Bu}$ noktada; arzulanan bireylerin yetiştirilmesi ve geliştirilmesi adına eğitim kurumlarına ve bu kurumların yöneticilerine yani okul müdürlerine çok önemli görevler düşmektedir. Çünkü geminin dümenindeki kaptan gemiyi yönlendirmede ne kadar etkin ve yetkili ise; eğitim sisteminin felsefesini, misyonunu ve amaçlarını bireylere ulaştırmada en kritik yerler olan okulların doğru ve başarılı yönetilip, sağlıklı bir okul kültürü ve iklimi oluşturmasında da okul müdürlerinin liderliği o derecede etkin ve tesirlidir.

\section{A. Yönetim ve Liderlik Kavramları}

\section{Yönetim ve Liderlik Kavramlarının Yapısı ve Tanımı}

Yönetim ile ilgili olarak, farklı bakış açılarına göre birçok tanım ve nitelemeler yapılmıştır. Genel anlamıyla yönetim, insanlar aracılığıyla işleri yaptır-

5 Drucker, Kendini yönetmek (Çev. İnan, M.), Esaslar: Harvard Business Review'den En Kalıcı Yönetim Fikirleri, İstanbul:Optimist Yayınları, 2012.

6 Drucker, a.g.e., s. 45

7 S. P.Robbins, \& T. A. Judge, Örgütsel davranış (Çev. Erdem, I.), Ankara:Nobel Yayınları, 14. Basım, 2012.

8 W. K. Hoy, \& C. G. Miskel, Eğitim yönetimi: Teori, araştırma ve uygulama (Çev. Turan S.), Ankara: Nobel Yayınları, 2010, s. 396.

9 F. C. Lunenburg, \& A. C. Ornstein, Eğitim yönetimi (Çev. Ed. Arastaman, G.), Ankara: Nobel Yayınları, 2013, s. 399.

10 Hoy, a.g.e., s. 375.

11 Hoy, a.g.e., s. 375. 
mak olarak tanımlanmaktadır. ${ }^{12}$ Daha geniş anlamıyla yönetim, önceden saptanan amaçlara ulaşmak için kaynakların organize edildiği ve gelecekteki faaliyetlerin belirlenmesi amacıyla sonuçların değerlendirildiği bir süreçtir. ${ }^{13}$ Maxwell ${ }^{14}$ yönetimi, yönettiği insanların mutluluğunu sağlamak için onları sevk ve idare etmek olarak tanımlamaktadır. Owen, Hodgson ve Gazzard ${ }^{15}$ ise yönetimi, hiyerarşik kuruluşlara düzen ve denetim getirmenin yolu olarak tanımlamaktadır. Drucker ${ }^{16}$ ise yönetimi farklı bir bakış açısıyla yorumlayarak şöyle nitelendirmektedir: Yönetim, yarının "bilgi işçileri”, öbür günün de yöneticileri olacak yüksekokul ve üniversitedeki gençler ile eğitimli insanları doğrudan etkileyen "inovasyon" dur. Drucker'ın bakış açısı bize; yönetimin gelecek tasarımında birey, toplum, kurum ve şirketlerden öte bir ülkenin yol haritasının ve gidişatının belirlenmesinde oynadığı kritik rolü tarif etmektedir.

Eren'in ${ }^{17}$ yaptığ1 yönetim tanımı, yönetim kavramının ihtiva ettiği süreç ve değişkenleri kapsar niteliktedir. Eren' ${ }^{18}$ göre yönetim, belirli bir takım amaçlara ulaşmak için başta insanlar olmak üzere parasal kaynakları, donanımı, demirbaşları, hammaddeleri, yardımcı malzemeleri ve zamanı birbiriyle uyumlu, verimli ve etkin kullanabilecek kararlar alma ve uygulatma süreçlerinin toplamıdır. Robbins, Decenzo ve Coulter ${ }^{19}$ de yönetimi, kimi işleri başkaları ile birlikte ve başkaları aracılığıyla etkin ve verimli bir şekilde yerine getirme süreci olarak tanımlamaktadır. Bu tanımdaki verimlilik, bir görevi doğru bir şekilde yapmak, en az kaynakla en fazla verimi elde etmek; etkinlik ise organizasyon hedeflerine ulaşacak şekilde eylemlerin tamamlanması ve doğru işlerin yapılması olarak açıklanmaktadır. ${ }^{20}$

Bununla ilgili olarak Stodgill, uzun çalışmaları sonrasında şöyle bir tespit yapmıştır; liderliğin, onu tanımlamaya çalışan insan kadar tanımı mevcuttur. ${ }^{21}$ Bu tanımlardan bazıları şöyle özetlenebilir:22 Liderlik, bir kişinin, paylaşılan bir amaç için bir grubun hareketlerini yönlendirmesidir. Liderlik, iki taraf arasında

12 R. M. Hodgetts, Yönetim: Teori, Süreç ve Uygulama (Çev. Çetin, C.; Can Mutlu, E.), İstanbul:Der Yayınları, 1997.

13 Hodgetts, a.g.e., s. 317.

14 J. C. Maxwell, Liderlik Nitelikleri (Çev. Pınarbaşı, A.), İstanbul:Beyaz Yayınları, 2012, s. 36.

15 H. Owen, V. Hodgson, \& N. Gazzard, Liderlik elkitabı (Çev. Çelik, M.), İstanbul:Optimist Yayınları, 2011, s. 66.

16 Drucker, a.g.e., s. 43.

17 E. Eren, Örgütsel davranış ve yönetim psikolojisi, İstanbul:Beta Yayınları, 14. Basım., 2012, s. 3.

18 Eren, a.g.e., s. 3.

19 S. P. Robbins, D. A.Decenzo, \& M. Coulter, Yönetimin Esasları (Çev. Öğüt, A.), Ankara:Nobel Yayınları, 2013, s. 6.

20 Robbins, Decenzo, \& Coulter, a.g.e., s. 6.

21 B. Temen, Liderlik Geliştirme, Aslan, A. E. (Ed.) Örgütte Kişisel Gelişim, Ankara:Nobel Yayınlar1, 2002, s. 166.

22 Temen, a.g.e., s. 166. 
olan bir etkileşimdir. Liderlik, belirlenmiş bir amaç ya da amaçlara ulaşmak için, kişilerarası etkinin iletişim yoluyla kullanılmasıdır. Liderlik, kişilerarası bir etkileşimdir. Liderlik, beklenti ve karşılıklı ilişkilerin başlamasını ve süregelmesini sağlayan etkidir.

Tüm bunlarla birlikte; Bernard Bass (The Bass Handbook of Leadership; Theory, Research and Managerial Aplications), Gary Yukl (Leadership in Organizations) ve Warren Bennis (Learning to Lead) tarafindan ortaya konan liderlik literatürüyle ilgili üç kapsamlı çalışma, bu fenomenin daha açık anlaşılmasına katkıda bulunmuştur. Bazı kavramsal anlaşmazlıklar olsa da çoğu uzman tarafından kabul edilen liderliğin tanımı şudur: Liderlik bireyin, tanımlanmış başarıya ya da örgütsel amaçlara ulaşmak için diğer grup üyelerini etkilediği süreçtir. ${ }^{23}$ Bu tanımda üç önemli boyut vardır: 1) Liderlik etki gerektirir; liderlik bir etkileme sürecidir. Etkileme süreci, bir liderin birden çok grup üyesinin ya da astın eylemlerini ya da tavırlarını değiştirdiği bir süreçtir. 2) Liderlik amaca ulaşmayı gerektirir; liderlik tanımlanmış grup amaçlarına ya da örgütsel amaçlara ulaşmak için etki sahibi olmayı gerektirir. Yani lider, belirli amaçlarla ilgili olarak, grup üyelerinin tutum ve davranışlarını değiştirmesine odaklanır. Bir grup ya da örgütün liderleri, bu etkiyi uygulayabilen bireylerdir. 3) Liderlik takipçileri gerektirir; etki süreci liderliğin karş11klı olduğunu işaret eder. Diğer bir ifadeyle liderler takipçilerini muhtelif şekillerde etkiler ve takipçilerinden etkilenir. ${ }^{24}$

\section{Dönüşümcü ve İşlemci Liderlik Stillerinin Yapısı ve Tanımı}

Burns ve Bass yapmış oldukları araştırmalar neticesinde liderlik kavramını; dönüşümcü ve işlemci (etkileşimci) liderlik olmak üzere iki ana başlık altında değerlendirmenin daha uygun olacağını ifade etmişlerdir. ${ }^{25}$ Burns ve Bass liderliği; daha geleneksel tarzlara bağlı, lider ile izleyenler arasında karşılıklı bir alışverişin olduğu, ödüllendirme prensibiyle hareket edilen etkileşimci liderlik ${ }^{26}$ ile liderin izleyenlerle-çalışanlarla arasında bir bağ kurduğu, çalışanları etkilediği, onlara rol-model olduğu, onları performanslarının ötesinde içtenlikle çalışmaya teşvik ettiği, takım ruhuyla hareket ederek birlik ve beraberlik içerisinde örgütün hedeflerini gerçekleştirmek konusunda çaba sarf ettiği, sürekli olarak yeniliği,

23 Lunenburg, \& Ornstein, a.g.e., s. 399.

24 Lunenburg \& Ornstein, a.g.e., s. 100.

25 G. Yukl, Managerial leadership: A review of theory and research, Journal of Management, 15(2), 1989, s. 251-289; B. J. Avolio, B. M. Bass, \& D. I. Jung, Re-examining the components of transformational and transactional leadership using the Multifactor Leadership Questionnaire, The Journal of Occupational and Organizational Psychology, 72, 1999, s. 441-462; B. M. Bass, Does the transactional - transformational leadership paradigm transcend organizational and national boundaries? American Psychologist, 52(2), 1997a, s. 130-139.

26 Yukl, a.g.e., s. 271; Bass, B. M., Jung D. I., Avolio, B. J., \& Berson, Y., Predicting unit performance by assessing transformational and transactional leadership, Journal of Applied Psychology, 88(2), 2003, s. 208 
değişimi ve gelişmeyi takip ederek, sert rekabet ortamında örgütü iri ve diri tuttuğu, başarılara sürekli olarak yaklaştırdığg dönüşümcü liderlik olmak üzere iki ana başlikta değerlendirmişlerdir. ${ }^{27}$

Dönüşümcü liderlik araştırmaları, liderlik alanında yapılan en önemli araştırmalar arasında gösterilmektedir. ${ }^{28}$ Özel ve kamu kesiminden birçok kurum ve kuruluş, bu liderlik araştırmalarının verilerinden hareketle kendi örgüt yapısını ve sistemini incelemişler, liderliğin örgütsel verimlilik ve başarı üzerindeki etkisini tespit etmişlerdir. Bu konuda, James McGregor Burns, yaygın şekilde dönüşümcü ve sürdürümcü liderlikle ilgili fikirler üzerine yaptığı çalışmalar ve onların da politik alanda uygulanması neticesinde dikkatleri üzerine çekmiştir. ${ }^{29}$ Burns'ün çalışmalarına binaen Bernard Bass, sosyal örgütlerde liderler için oldukça geniş, kapsamlı ve etkili bir model oluşturmuştur. ${ }^{30}$ Bass, yaptığı çalışmalarla, hem dönüşümcü hem de etkileşimci liderliğe odaklanan bir yaklaşım geliştirmiştir. ${ }^{31}$ Ancak son zamanlardaki araştırmalar genellikle; dönüşümcü liderleri, etkileşimci liderlerden ayırma üzerine odaklanmaktadır. ${ }^{32}$

\section{Dönüşümcü Liderlik Stilinin Alt Boyutları}

Genel olarak dönüşümcü liderlik alt boyutları; karizma, telkinle güdüleme ve entelektüel uyarım ve bireysel ilgi olmak üzere dört başlık altında değerlendirilmektedir. $^{33}$

1. İdealleştirilmiş etki-Karizma: Lider kendisine hayran olunan, güven duyulan, sayg1 gösterilen bir kişidir. Lider izleyenleri için rol-model olur. Lider izleyenlere önem verir, onlara saygı gösterir, örgütün misyon, vizyon ve hedeflerini izleyenlerle açıkça paylaşarak, izleyenler üzerinde güçlü bir etki oluşturur. İzleyenler, liderin hedeflere ulaşma konusunda elde ettikleri başarıları gördükçe onun tutum ve davranışlarını daha çok modellemeye başlar ve onun gibi olmaya çalışır. İdealleştirilmiş etki sayesinde liderler; izleyenlerin beklentilerin ötesinde ekstra çalışmalarını sağlayarak, örgüt menfaatleri adına daha çok gayret sarf etmelerini temin ederler.

27 Yukl, a.g.e., s. 272 ; Bass, a.g.e., s. 131; S. B. MacKenzie, P. M. Podsakoff, , \& G. A. Rich, Transformational and transactional leadership and salesperson performance, Journal of the Academy of Marketing Science, 29(2), 2001, s. 115-134; Avolio, Bass, \& Jung, a.g.m., s. 460.

28 Hoy, a.g.e., s. 395.

29 Hoy, a.g.e., s. 396.

30 Hoy, a.g.e., s. 397.

31 Burns, a.g.e. ; B. Bass, Leadership and Performance Beyond Expectations, New Yok:Free Press, 1985; Bass, Jung, Avolio \& Berson, a.g.m, s. 208; Lunenburg, \& Ornstein, a.g.e., s.127.

32 Lunenburg \& Ornstein, a.g.e., s. 127

33 Bass, a.g.e, s.133; Bass, Jung, Avolio \& Berson, a.g.m, s. 208; Eagly, A. H., Johannesen-Schmidt, M. C., \& Van Engen, M. L., Transformational, transactional and Laissez-Faire leadership styles: A meta-analysis comparing women and men, Psychological Bulletin, 129(4), 2003 , s. 571 
2. Telkinle güdüleme: Lider, örgütün hedefleri ve amaçları konusunda, izleyenleri motive eder ve onları cesaretlendirir. Basit ve anlaşılır bir üslupla, örgütün hedeflerine ulaşma konusunda çalışanları daha çok gayret göstermeleri konusunda teşvik eder; daha verimli bir çalışma ortamı için örgüt içerisinde takım ruhu oluşturur. Örgüt içerisinde, coşku ve iyimserlik duygusunun hakim olduğu bir atmosfer hazırlar. Lider, izleyenlerine, çok çalışmaları halinde gelecekte, kendilerini bekleyen çok güzel sonuçların olduğunu söyler ve bu durumun izleyenler tarafindan hayal edilmesini temin eder.

3. Entelektüel uyarım: Lider, izleyenlerini, yaşanan olaylar, durumlar ve sorunlara yeni ve farklı bakış açısıyla yaklaşmaları konusunda cesaretlendirir. Lider, izleyenlerden, sorunları yeniden analiz etmelerini, yaşanan süreçler karşısında farklı bakış açıları ve anlayışlar oluşturarak; problemlerin altında yatan sebepleri bu perspektifler yardımıyla tekrar gözden geçirmelerini ister. İzleyenlerin ortaya koyduğu çözüm önerileri ve yeni fikirler neticesinde kendilerine karş1 olumsuz tavır sergilenmemesi, rahatsız edici ve incitici eleştirilerin oluşmaması için gerekli olan özgür ve hoşgörülü örgüt iklimini hazırlar. Lider, sahip olduğu olumlu özelliklerin de yardımıyla yenilikçi, girişimci, olaylara farklı açılardan yaklaşabilen izleyenleri yetiştirir ve geliştirir.

4. Bireysel ilgi: Lider, çalışanlarının bireysel farklılıklarını ve ihtiyaçlarını gözetir, bunlara gerekli önemi vererek, sahip oldukları farklı imkan ve kabiliyetlerini tespit eder ve onların başarabileceği hedefler koyar. Lider, çalışanlarına karşı bir mentor ve rehber olarak hareket eder, onların gelişmesi için yeni öğrenme ortamları hazırlar; öğrenmeyi ve gelişimi destekleyen bir örgüt iklimi oluşturur. Bu sayede çalışanlar, sahip oldukları imkan ve kabiliyetlerinin zirvesine ulaşır ve bunları da örgütün başarı ve menfaati için kullanır.

\section{4. İşlemci Liderlik Stilinin Alt Boyutları}

İşlemci liderlik alt boyutları ise koşullu ödül, istisnalarla yönetim ve tam serbestlik tanıyan liderlik olmak üzere üç başlık altında değerlendirilmektedir: ${ }^{34}$

1. Koşullu ödül: Lider, izleyenleri, örgütün kendilerinden beklentileri konusunda açıkça bilgilendirir; bu beklentilerin karşılanması durumunda kendilerinin ödüllendirileceğini ifade eder. Lider, çalışanlarını ortaya koydukları performans ve sonuçlara göre ödüllendirir; bu mantığa göre onları yönetir. İyi performans ödüllendirilir, başarılar takdir edilir; performans ve başarı karşılığında çalışanlara ödül sözü verilerek karşılıklı bir anlaşmaya varılır. Adeta, lider ile çalışanlar arasında performans ve ödül konusunda bir değiş-tokuş gerçekleşir.

34 MacKenzie, Podsakoff \& Rich, a.g.m., s. 116; Bass, a.g.e, s.130-139; Bass, B. M., Jung D. I., Avolio, B. J., \& Berson, Y., a.g.m, s. 208; Eagly, Johannesen-Schmidt \& Van Engen, a.g.m., s. 571. 
2. İstisnalarla yönetim: İstisnalarla yönetim kendi içerisinde aktif ve pasif olmak üzere ikiye ayrılır:

a. Aktif istisnalarla yönetim: Lider çalışanlarını ve ortaya koydukları performanslarını gözler. Standartlardan ve kurallardan bir sapma olursa lider, duruma müdahale ederek hatayı düzeltir. Hatalardan uzak durulması için kural ve prensiplere bağlı kalınması konusunda 1srarcı olur.

b. Pasif istisnalarla yönetim: Lider, problemlerin ciddi bir sorun haline gelmesine kadar sisteme müdahale etmez. Ne zaman ki yaşanan aksaklıklar ileri boyuta varır, herkesin dikkatini çeker ve sistemi sıkıntıya sokarsa lider harekete geçer ve olaylara müdahale eder.

3. Tam serbestlik tanlyan liderlik: Lider; hareketsiz, etkisiz, kararsiz ve isteksizdir. Lider, sorumluluk almaktan kaçınır; çalışanları ve sistemi kendi haline bırakır; kendisine ihtiyaç duyulan durumlarda sistemde ve yönetimde yoktur. Örgütün hedef ve amaçlarını izleyenlere açıklamak, onları motive etmek ve onlara destek olmak konusunda başarısızdır.

\section{B. Dönüşümcü ve İşlemci Liderlik Stillerinin Eğitim Örgütleri Açısından Etkileri}

Dönüşümcü ve işlemci liderlik ile kurumların yapıları ve başarı ya da başarısızlıkları arasında önemli bağlantılar vardır. Dönüşümcü ve işlemci liderliğin ayrı ayrı kurumsal yapıya ve kurum kültürüne etkileri bulunmaktadır.

\section{Dönüşümcü Liderin Özellikleri ve Örgütsel Etkileri}

Dönüşümcü liderler, çalışanlarıyla arasında kuvvetli bir bağ oluştururlar; çalışanlarını örgütün menfaatleri konusunda yönlendirirler; ${ }^{35}$ çalışanlarını kendi kişisel çıkarlarından uzaklaştırarak örgütün başarısı için daha çok çalışmak ve fedakarlık yapmak konusunda derin bir şekilde etkilerler. ${ }^{36}$ Bu konuda onlara rol-model olarak, rehberlik ederler, örgüt için adanmalarını sağlarlar. ${ }^{37}$ Çalışanların inançlarını, değerlerini ve ihtiyaçlarını iyi analiz eder ve tanırlar; ${ }^{38}$ bu sayede onların bireysel farklılıklarını dikkate alarak onları motive ederler ve beklentilerin ötesinde performans sergileme konusunda teşvik ederler; ${ }^{39}$ çalışanlarına

35 Bass, a.g.e, s. 130

36 R. J. Deluga, The effects of transformational, transactional and Laissez Faire leadership characteristics on subordinate influencing behavior, Basic and Applied Social Psychology, 11(2), 1990, s. 193.

37 K. Leithwood, The move toward transformational leadership, Educational Leadership, 49(5), 1992a, s. 9.

38 W. L. Koh, R. M.Steers, \& J.R. Terborg, The effects of transformational leadership on teacher attitudes and student performance in Singapore, Journal of Organizational Behavior, 16(4), 1995 , s. 320.

39 K. Leithwood, T. Menzies, D. Jantzi, \& J. Leithwood, School restructuring, transformational leadership and the amelioration of teacher burnout, Anxiety, Stress and Coping: An International Journal, 9(3), 1996, s. 203. 
imkan ve kabiliyetleriyle uyumlu görevler vererek başarı duygusunu tatmalarını ve kendilerine daha çok güvenmelerini temin ederler; ${ }^{40}$ sürekli olarak kişisel ve kurumsal gelişim içindedirler; ${ }^{41}$ bitmek tükenmek bilmeyen bir enerji ve istekle yeniliğin peşinden koşarlar, girişimcidirler, yenilikçidirler; ${ }^{42}$ olaylara ve sorunlara farklı açılardan bakarak yeni çıkarımlarda bulunurlar, esnek çözümler üretirler; ${ }^{43}$ zamanın ve rekabet ortamının gereklilikleriyle uyumlu şekilde örgütün misyon, vizyon, değerler ve stratejik planlamasında ihtiyaç duyulan değişiklikleri yerine getirirler. ${ }^{44} \mathrm{Bu}$ liderlik tarzı; özellikle değişimin baş döndürücü şekilde yaşandığı, bilim ve teknolojinin son derece hızlı gelişip, yayıldığı; rekabetin çok sert yaşandığ 1 , örgütlerin yerel ve global düzeyde başarılı olabilmeleri, sorunlarla başa çıkıp varlıklarını devam ettirebilmeleri, değişen şartlara hızlı uyum sağlayabilmeleri için hızlı ve esnek çözümler üretebilmeleri, bireysel özelliklere göre yönetim kurgusunun tekrar yapılandırıldığı, ekiple hareket ederek, takım ruhuyla çalışmaların başarıya ulaştırıldığg günümüz koşullarında, başarıya daha yakın olan bir liderlik anlayışıdır ${ }^{45}$.

\section{2. İşlemci Liderin Özellikleri ve Örgütsel Etkileri}

İşlemci liderler, örgütün önceden gelen işleyiş sistemine pek müdahale etmezler; ${ }^{46}$ çalışanlarını ödüllendirme ile motive ederler, başarılar karşısında çalışanlarına makam, statü, para vaat ederler ${ }^{47}$ çalışanların bireysel özellikleriyle, girişimci ve yenilikçi yanlarıyla pek ilgilenmezler ${ }^{48}$ faaliyetler örgütün temel misyon ve vizyonu çerçevesinde bu şekilde sürüp gider. ${ }^{49} \mathrm{Bu}$ liderlik tarzı; örgütün misyon, vizyon ve değerleri çerçevesinde örgütü yönetmek, sistemi sevk ve idare etmek konusunda faydalıdır. ${ }^{50}$ Ancak, günümüz rekabet ortamında adeta bir zorunluluk olan yenilikçilik, girişimcilik, reform, ihtiyaçlar karşısında örgütü

40 K. A. Hipp, Documenting the effects of transformational leadership behavior on teacher efficacy, Paper presented at the annual meeting of the American Educational Research Association, Chicago, 1997, s. 4.

41 Bogler, a.g.m, s. 663

42 J. L. Bess, \& P. Goldman, Leadership ambiguity in universities and K-12 scools and the limits of contemporary leadership theory, The Leadership Quarterly, 12, 2001, s. 419-450.

43 Barnett, McCormick \& Conners, a.g.m, s. 42.

44 F. Geijsel, P. Sleegers, K.Leithwood \& D. Jantzi, Transformational leadership effects on teachers' commitment and effort toward school reform, Journal of Educational Administration, 41(3), 2003, s. 228-256.

45 Yukl, a.g.e., s. 271; J. M. Howell, \& B. J. Avolio, Transformational leadership, transactional leadership, locus of control, and support for innovation: Key predictors of consolidated-business-unit performance, Journal of Applied Psychology, 78(6), 1993, s. 891-902;. MacKenzie, Podsakoff \& Rich, a.g.m., s. 118.

46 Bass, a.g.e, s. 134.

47 Howell \& Avolio, a.g.e, s. 891.

48 Deluga, a.g.e, s. 192.

49 MacKenzie, Podsakoff \& Rich, a.g.m., s. 118; Bass, Jung, Avolio \& Berson, a.g.m, s. 208.

50 Bass, a.g.e, s. 134. 
ve kurumsal yapıyı hızlıca yeniden organize etmek, çalışanlarla bir ve beraber olup, ekip ruhuyla hareket ederek beklentilerin ötesinde ürünler ortaya koymak noktasında zayıftır. ${ }^{51}$

\section{Eğitim Örgütleri Açısından Dönüşümcü ve İşlemci Liderlik Stilleri}

Eğitim sistemindeki sorunların ortadan kaldırılması ve başarılı bir yapının oluşturulması; temelde, "okulun" gerçek manada etkili, verimli ve başarılı yönetilmesiyle mümkün olabilecektir. ${ }^{52}$ Okul, herkes için bir yaşama ve öğrenme yeri olup eğitim etkinliklerinin merkezinde insan vardır. ${ }^{53}$ Okul, hayatın anlamland1rıldığ1 ve kurgulandığ 1 bir yerdir. ${ }^{54} \mathrm{Bu}$ bağlamda okul müdürü, okulun ve okul programının yönetiminden, öğrenmenin gerçekleştirilmesinden ve okulun başarısından birinci derecede sorumlu görülen kişidir. ${ }^{55} \mathrm{Bu}$ nedenle okulun başarı ya da başarısızlığı, bir bakıma müdürün başarı ya da başarısızlığı ile açıklanır. Okulun yönetiminde en yetkili kişi olarak müdürün sahip olduğu yasal güç ve yetkiler, onun okulu yönetmesinde ve başarılı kılmasında tek başına yeterli değildir. ${ }^{56} \mathrm{Bu}$ noktada okul müdürünün göstereceği liderlik özelliklerinin önemi karşımıza çıkmaktadır.

Hemen hemen tüm etkili okul araştırmaları, okul müdürünün okulun etkinliğinde, sağl1klı bir okul kültürü ve iklimi oluşturulmasında anahtar bir rol oynadığı gerçeğini ispat etmektedir. ${ }^{57}$ Okul müdürünün liderlik becerisi ve özellikleri, etkili okul kültürünün temel belirleyicilerinden biridir. Okul müdürünün liderlik stili ile okul kültürü arasında ciddi bir ilişkinin olduğu konusunda görüş birliği vardır. ${ }^{58}$ Etkili okul müdürleri, kaynakları etkili şekilde kullanarak, öğretimsel etkililiği artırmayı ve öğrenci başarısını en üst düzeye çıkarmayı amaçlar; okul programlarının geliştirilmesine, öğrenme ve öğretme ortamının düzenlenmesine, kurum kültürünün oluşturulmasına, çalışanların kendilerini sürekli geliştirmelerine ve örgütsel başarının sağlanmasına büyük önem verirler. ${ }^{59}$ Okul müdürlerinin liderlik stillerinin, sağlıklı bir okul kültürü ve ikliminin oluşturulmasında ve okulun örgütsel amaçlarına ulaşmasında çok önemli bir faktör olduğu yapılan araş-

51 Yukl, a.g.e., s. 271; MacKenzie, Podsakoff \& Rich, a.g.m., s. 118.

52 S. Turan, Işsini bil okuluna sahip ol, Açıkalın, A.; Şişman, M.; Turan, S. (Ed.) Okul müdürü, Ankara:Pegem A. Yayınları, 2007, s. 82

53 S. Turan, a.g.e., s.82.

54 A. Açıkalın, Ete kemiğe büründük müdür diye göründük, Açıkalın, A.; Şişman, M.; Turan, S. (Ed.) Okul Müdürü, Ankara:Pegem A. Yayınları, 2007, s. 5

55 M. Şişman, Öğretim liderliği. Ankara:Pegem A. Yayınları, 4. Basım, 2012, s.2

56 Şişman, a.g.e., s. 2.

57 A. Balc1, Etkili okul geliştirme: Kuram, uygulama ve araştırma, Ankara:Pegem A. Yayınları, 4. Basim, 2007, s. 113

58 Balc1, a.g.e., s.113

59 V. Çelik, Eğitimsel Lliderlik, Ankara:Pegem A. Yayınları, 7. Basım, 2013, s.46 ; A. Balcı, a.g.e., 113 
tırmalar neticesinde ortaya çıkmaktadır. ${ }^{60}$ Araştırmalar, örgütsel amaçlara ulaşmada dönüşümsel liderlik tarzının, geleneksel formları içeren işlemci liderlikten daha fazla etkili olduğunu göstermektedir. Aynı şekilde yapılan araştırmalar; dönüşümsel liderliğin, işlemci liderliğe göre çalışanların motivasyon ve performansını artırmada, örgütsel bağlılı̆̆ın oluşturulmasında ve örgütsel vatandaşlığın tesis edilmesinde daha etkin ve önemli olduğunu göstermektedir. ${ }^{61}$

Eğitim örgütlerinde beklenilen ve istenilen sonuçları elde etme noktasında, dönüşümcü liderlik çok önemli bir yere sahiptir. ${ }^{62}$ Dönüşümcü liderlik özelliğine sahip bir okul müdürü; öğretmenler başta olmak üzere okuldaki tüm çalışanlarla birlik ve beraberlik içinde hareket eder; ${ }^{63}$ okulun hedeflerinin gerçekleştirilmesi konusunda vizyoner ve karizmatik kişilikleriyle öğretmenlere rol-model olur; ${ }^{64}$ öğretmenlerin kayg1, stres ve tükenmişlik duygularına kapılmaması, güçlü ve istekli olmaları için öğretmenlere destek olur; ${ }^{65}$ girişimci, yenilikçi, etik değerlere sayg1l1, adaletli, ilkeli ve erdemlidir; ${ }^{66}$ teknolojiyi ve bilimsel gelişmeleri takip ederek okullarını bu veriler çerçevesinde yeniler, değiştirir ve geliştirir. ${ }^{67}$ Aynı şekilde dönüşümcü liderlik özelliğine sahip bir okul müdürü, öğretmenlerine öğretimsel açıdan liderlik eder; ${ }^{68}$ öğretmenlerin bireysel farklılıklarına dikkat ederek, onların

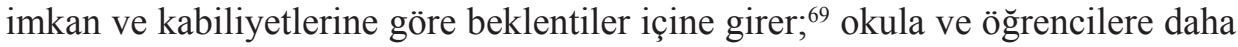
verimli olmaları adına öğretmenlerin kişisel ve kurumsal gelişimleri için çaba gösterir ve öğrenen örgüt kültürünü oluşturur; ${ }^{70}$ sağlıklı bir çalışma ortamı ha-

60 M. Korkmaz, Duyguların ve liderlik stillerinin öğretmenlerin performansı üzerinde etkisi, $K u$ ram ve Uygulamada Eğitim Yönetimi (Educational Administration: Theory and Practice), 43, 2005, s. 402.

61 Hoy \& Miskel, a.g.m., s.399; Lunenburg, \& Ornstein, a.g.e., s. 127; Drucker, a.g.m., s. 237

62 Leithwood, a.g.m., s., 10; Pounder, Ogawa \& Adams, a.g.m., s. 586.

63 Leithwood, a.g.m., s. 9; Barnett, McCormick \& Conners, a.g.m., s. 26.

64 Geijsel, Sleegers, Leithwood, \& Jantzi, a.g.m., s. 239.

65 Leithwood, Menzies, Jantzi, \& Leithwood, a.g.m., s. 212; S. R. Decker, The relationship among principal power tactic usage, leadership style and school climate in selected Iowa elementary schools, Unpublished doctoral dissertation, University of Northern Iowa, Cedar Falls, 1989, s.212; B. P. Miller, Leadership, organizational culture, and managing change: A case study of North Carolina's Johnston Community College, Unpublished doctoral dissertation, North Carolina State University, Raleigh, 2001, s.27; Reeves, T. L., Principal leadership and the development of organizational culture in a new school, Unpublished doctoral dissertation, The University of North Carolina, Chapel Hill, 2006, s. 94.

66 W. K. Hoy, \& C. J. Tarter, Organizational justice in schools: No justice without trust, International Journal of Educational Management, 18 (4), 2004, s. 254; Jr. W. D. Greenfield, , Moral leadership in schools, Journal of Educational Administration, 42(2), 2004, s. 180.

67 M. E., Anderson, Principals, how to train, recruit, select, induct, and evaluate leaders for America's schools, Unpublished doctoral dissertation, University of Oregon, Eugene, 1991, s. 22.

68 T. J. Larsen, Identification of instructional leadership behaviors and the impact of their implementatin on academic achievement, Unpublished doctoral dissertation, University of Colorado Boulder, Boulder, 1985, s.21; Barnett, McCormick \& Conners, a.g.e, s. 27.

69 H. Silins, \& B. Mulford, Schools as learning organisations-effects on teacher leadership and student outcomes, Schools Effectiveness and Scholl Improvement, 15(3-4), 2004, s. 445.

70 Leithwood, \& Jantazi, a.g.m., s. 204; Miller, a.g.m., s.39; B. C. Herndon, An analysis of the relationships between servant leadership, school culture, and student achievement, Unpublished doctoral dissertation, University of Missouri, Columbia, 2007, s.42. 
zırlar. $^{71}$ Dönüşümcü liderlik özelliklerine sahip okul müdürleri; öğretmenlerin kendilerini ifade edebildiği, olaylar, durumlar ve sorunlar karşısında farklı fikir ve düşüncelerini rahatlıkla ortaya koyabildiği, okulun hedefleriyle özdeşleştiği; gelişmeye açık, hoşgörülü bir iklim için çaba sarf eder; ${ }^{72}$ öğretmenlerinin bireysel özelliklerini dikkate alarak her birini en uygun şekilde motive eder, cesaretlendirir ve teşvik eder ${ }^{73}$ başarılı ve mutlu öğrencilerin yetişmesi için başarılı ve mutlu öğretmenlerin bulunması gerektiğinin bilincinde olarak okulu yönetir. ${ }^{74}$

74 Leithwood \& Jantzi, a.g.m., s.224; Pounder, Ogawa \& Adams, a.g.m., s. 585; Bogler, a.g.m, s. 679; Herndon, a.g.m., s.52. 


\section{Sonuç ve Öneriler}

Okul müdürlerinin liderlik özellikleri, okulda çalışanlar başta olmak üzere okulda hissedilen örgütsel güveni, bağl1lığı ve vatandaşlığı, okulun kültür ve iklimi ile eğitim ve öğretimin kalitesini doğrudan etkilemektedir. Okul müdürlerinin sahip olduğu kişisel ve mesleki özellikler, kullandıkları iletişim ve yönetim biçimleri, okulun maddi ve manevi özelliklerini, okuldaki tüm personelin fiziksel ve psikolojik yapısını önemli ölçüde belirlemektedir. Okul müdürlerinin sahip oldukları liderlik özellikleri, öğretmenlere esin kaynağı olabilmeli ve onları yönlendirebilmelidir. Bununla birlikte, okul müdürlerinin sahip oldukları liderlik özellikleri, okulda gerçekleştirilecek değişimin itici gücü olmalarının yanı sıra, herhangi bir sorunla karşılaşıldığında, bu sorunu en hızlı ve etkili şekilde çözebilecek yetkinlikte olmalıdır. Okul müdürlerinin sahip oldukları liderlik özellikleri, adeta bir çimento gibi okulun maddi ve manevi tüm öğelerini bir araya getirmeli ve onların arasında insicamlı bir bütünlük oluşturmalıdır.

Okul müdürü, okulu, huzurlu veya huzursuz edebilecek aynı zamanda okulun başarı ya da başarısızlı̆̆ını belirleyecek en önemli faktördür. Buradan hareketle, okul müdürlerinin dönüşümsel liderlik özelliklerini geliştirme konusunda çaba sarf etmelerinin çok önemli olduğu sonucuna ulaşılabilir. Ülkemizi dünyada lider ülke haline getirebilecek insan kaynağına sahip olabilmemize temel teşkil eden eğitim kurumlarının istenileni verebilmesi, okuldaki eğitim ve öğretimin verimli olması, okulların milli eğitim sisteminde belirtildiği üzere yönetilmesi büyük oranda okul müdürlerine bağlıdır. Okul müdürünün kişisel ve mesleki özellikleri ile yapısı, okulun başarı ve başarısızlığının ana belirleyicisi olmaktadır.

Eğitim kurumlarında görev yapan müdürlerin gösterdikleri dönüşümsel liderlik stili, okulu ve okulla ilgili tüm paydaşları olumlu şekilde etkilemektedir. Bu durum öğretmenlere ve çalışanlara da olumlu şekilde yansımakta, eğitim ve öğretimin başarılı olmasına destek olmaktadır. Okul müdürlerinin dönüşümcü liderlik özellikleri ne kadar yüksek ise öğretmenlerin sergiledikleri örgütsel güven, bağl11ık ve vatandaşlık davranışı seviyesi; olumlu ve sağlıklı örgüt yapısı ile örgütün performans ve başarı endeksleri de o kadar yüksek olmaktadır.

Dönüşümcü liderlik özelliğine sahip okul müdürleri; olumlu kişilik özelliklerine sahiptir, makul ve mantıklı hedefler belirler, yenilikçi (inovatif) ve girişimcidirler, etkili çalışma ve iş kültürüne sahiptirler, etkili iletişim kurarlar, çalışanlarına önem verirler ve motive ederler, ekip-takım çalışmasına önem verirler, sorun çözme becerilerini geliştirmişlerdir. Bu açıdan bakıldığında, okul müdürünün dönüşümcü liderlik özelliklerine sahip olması, ulaşılması istenen hedefler için çok kritik bir noktadır ve bu husus hiçbir zaman gözden uzak tutulmamalıdır.

Günümüzde baş döndürücü hızla gelişen yeniliklerle birlikte; örgütlerdeki, iş ve insan faktöründeki yaşanılan değişimler liderliği çok önemli hale getirmekte 
ve liderlik özelliği taşıyan yöneticilere olan ihtiyacı artırmaktadır. Eğitim kurumlarının en değerli kaynağ 1 olan öğretmenlerin doğru yönlendirilmesi ve desteklenmesi, olumlu örgüt kültürünün oluşturulması ve sağlıklı okul ikliminin tesis edilmesi açısından dönüşümcü liderlik hayati önem taşımaktadır. Örgütlerin yüksek performansla çalışabilmesi; verimliliğin artırılması, sağlıklı, girişimci, yenilikçi, tüm çalışanların bir ve beraber olarak örgütün hedeflerine doğru koşabilmesi, örgütün menfaatleri doğrultusunda kişisel ve kurumsal gelişimin her zaman ön planda tutulduğu, beklentilerin ötesinde çalış1larak ekstra gayretlerin ortaya konulduğu, çalışanlar arasında "biz büyük bir aileyiz" kültürünün oluşturularak, örgütün vizyon, misyon, değer ve hedeflerine adanılmış bir örgütsel güvenin, bağl1lığın ve vatandaşlığın ortaya konabilmesinde de dönüşümcü liderlik kilit bir rol oynamaktadır. Günümüzde lider, kurumların yönetilmesindeki en önemli ve belirleyici aktördür.

$\mathrm{Bu}$ tespitlerden hareketle önerilerimizi şu başlıklar altında toplayabiliriz:

\section{Uygulayıcılar için öneriler,}

- Okul müdürlerinin dönüşümcü liderlik özelliklerini geliştirecek, yöneticilik eğitimleri, konferans, seminer, panel gibi bilimsel toplant1 etkinlikleri ve hizmet içi eğitimler organize edilmelidir. Aynı şekilde, okul müdürleri ve üst düzey yöneticiler için; öğrenci, öğretmen, veli iletişimi ve insan psikolojisi ile ilgili eğitimler ilçe ve il bazında planlanmalı ve periyodik olarak da tekrarlanmalıdır. Okul ikliminin en önemli belirleyicisi durumunda olan yöneticiler sürekli olarak bu konularda bilinçlendirilmelidir.

- Okul müdürleri, kendi aralarında bir araya gelerek başarılı liderlik örnekleri üzerinde konuşmalı, istişare etmeli ve tecrübe paylaşımı yapmalıdır. Milli eğitim müdürlükleri, başarılı liderlik örneklerini içeren, sisteme aktif katkı verebilecek ve müdürlere yol gösterebilecek örnek vakaların olduğu kitaplar yayınlamalı ve müdürlerin bunlardan en güzel şekilde istifade etmesini sağlamalıdır.

- Okul yöneticilerine, eğitim ve öğretimin etkili ve verimli olmasında, öğretmenlerin iş doyumu ve yüksek performanslarında çok önemli bir kavram olduğu anlatılmalı ve bu hususlarda okul müdürlerinin yeterlilik kazanmaları sağlanmalidir.

- Okul yöneticisi, sağlam ve sağlıklı bir kurum kültürü oluşması adına, tüm çalışanları ile ilgili verilecek kararlarda adaletten ve objektiflikten ayrılmamalı; verdiği vaatleri yerine getirmede, ödüllendirme, terfi, performans değerlendirme gibi konularda adil bir yönetim anlayışı sergilemeli; tüm çalışanların kendisi ve kurum için eşit ve çok önemli olduğunu her firsatta hissettirmelidir.

- Okul müdürleri, okul ve öğretmenler için yaptığı etkinlikleri okul içinde ve dışındakilere anlatma noktasında başarılı olmalıdır. Çünkü okulda olumlu bir örgüt iklimi oluşturulmasından ve örgütsel vatandaşlı̆̆ın tesisinden birinci de- 
recede sorumlu olan yöneticinin, öğretmenlerce algılanma biçimi; öğretmenlerin kendilerini işlerine adamalarına, yeteneklerini ve bilgilerini en üst düzeyde kullanma isteğine, bir eğitimci olarak potansiyellerini olabildiğince çok hizmete adamalarına doğrudan etki edecektir.

- Okul yöneticileri ve öğretmenler, sürekli gelişim ve yeniliğe bağlılık ile okul başarısını yükseltme adına, Eğitim Yönetimi Denetimi Planlaması ve Ekonomisi bölümünde lisansüstü programlara katılmaya teşvik edilmelidir.

- Okullarda dönüşümcü liderliğe katk1 verecek, öğretmenlerin mesleklerindeki gelişmeleri ve yenilikleri zamanında ve yerinde takip etmelerine olanak sağlayacak yayınlara özellikle yer verilmelidir.

- Eğitim Fakültelerinde "Eğitim Yönetimi”, "Okul Yönetiminde Liderlik" "Liderlik ve Örgütsel Vatandaşlık", "Liderlik ve Kurumsal Başarı", gibi derslerin verilmesi liderlik konusuna farkındalık kazandırılması açısından faydalı olacaktır. Buradan hareketle, bu ve buna benzer içerikli derslerin sayısı artırılmalıdır.

\section{Araştırmacılar için öneriler,}

- Lisans ve lisansüstü çalışmalarda, eğitim kurumlarında okul müdürlerinin yönetim becerileri ile etkili ve verimli eğitim öğretim ortamının tesisine yönelik araştırma ve çalışmalara özellikle ağırlık verilebilir. Yurt içi ve yurt dişı ilgili yayınlar takip edilerek, çağdaş ve yeni modeller geliştirilerek milli eğitim sistemimizin gelişmesine katkı sağlanabilir.

- Liderlik ve örgütsel vatandaşlık davranışı ile okul kültürü, okulların başarı düzeyleri, yönetici, öğretmen ve öğrencilerin moral ve iş doyumları gibi değişkenlerin karşılaştırmalı olarak incelendiği araştırmalar yapılabilir.

- Çağdaş ve yeni gelişmeler 1şığında okullarımızın etkili ve verimli olması adına ülkemize has liderlik modelleri üzerinde çalış1labilir. Bunun için de teori ile pratiği iç içe yaşatmalı ve birbiriyle at başı koşturmalıdır.

Geleceğe yönelik olarak, okul müdürlerinin liderlik stillerinin, yapısal durumunun, alt boyutlarının ve özelliklerinin yeni gelişmeler ve güncel veriler 1şığında yeniden tasarlanması, Türkiye'nin farklı bölgelerinde geniş kitlelere uygulanması ve elde edilecek verilerle ülkemiz eğitim sistemine hizmet etmesi önemli bir zenginlik olacaktır. 


\section{Kaynakça}

Açıkalın, A.-Şişman, M.-Turan, S., Bir Insan Olarak Okul Müdürü, Ankara, Pegem A. Yayınları, 2007.

Açıkalın, Ş. Ş., "Öğretmenlerin okul müdürlerini etkileme güçleri”, $H$. $\ddot{U}$. Ĕ̈itim Fakültesi Dergisi, 9, 1993.

Akbaba-Altun, S., "İlköğretim okulu müdürlerinin dönüşümcü liderliğe verdikleri önem ve uygulama düzeyleri”, İlköğretim-Online, 2 (1), 2003.

Aksu, A.-Fırat, N. Ş.-Şahin, İ., "Cultural leadership behaviours of primary school principals", Kuram ve Uygulamada Eğitim Yönetimi (Educational Administration: Theory and Practice), 36, 2003.

Alimo Metcalfe, B.-Alban Metcalfe, R. J., "The development of a new transformational leadership questionnaire", Journal of Occupational and Organizational Psychology, 74, 2001.

Anderson, M. E., "Principals, how to train, recruit, select, induct, and evaluate leaders for America's schools", (Unpublished doctoral dissertation), University of Oregon, Eugene, 1991.

Arslantaş, C. C.-Pekdemir, I., "Dönüşümcü liderlik, örgütsel vatandaşl1k davranış1 ve örgütsel adalet arasındaki ilişkileri belirlemeye yönelik görgül bir araştırma", Anadolu Üniversitesi, Sosyal Bilimler Dergisi, 7 (1), 2007.

Avolio, B. J.- Bass, B. M., "MLQ-Multifactor leadership questionnaire", $C A$ : Mindgarden, Inc. USA, 1995.

Avolio, B. J., Bass- B. M.- Jung, D. I., "Re-examining the components of transformational and transactional leadership using the Multifactor Leadership Questionnaire", The Journal of Occupational and Organizational Psychology, 72, 1999.

Balc1, A., Etkili okul geliştirme: Kuram, uygulama ve araştırma, 4. bs., Ankara, Pegem A. Yayınları, 2007.

Barnett, K.-McCormick, J.-Conners R., "Transformastional leadership in schools - Panacea, placebo or problem", Journal of Educational Administration, 39 (1), 1999.

Bass, B., Leadership and Performance Beyond Expectations, New Yok, Free Press, 1985.

Bass, B. M., "Does the transactional - transformational leadership paradigm transcend organizational and national boundaries?", American Psychologist, 52 (2), 1997.

, "Personal selling and transactional/transformational lead- 
ership", Journal of Personal Selling and Sales Management, 17 (3), 1997.

,"Two decades of research and development in transformational leadership", European Journal of Work and Organizational Psychology, 8 (1), 1999.

, The Bass Handbook of Leadership, Theory, Research, and Managerial applications, New York, Free Press, 2008.

Bass, B. M.-Avolio, B. J., "Transformational leadership and organizational culture”, Public Administration Quarterly, 17, 1993.

Bass, B. M.-Steidlmeier, P., "Ethics, character, and authentic transformational leadership behavior", The Leadership Quarterly, 10 (2), 1999.

Bass, B. M.-Jung D. I., Avolio, B. J.- Berson, Y., "Predicting unit performance by assessing transformational and transactional leadership", Journal of Applied Psychology, 88 (2), 2003.

Bennis, W.-Goldsmith, J., Learning to lead, a workbook on becoming a leader, Cambridge, Perseus Books, 1997.

Bess J. L.- Goldman P., "Leadership ambiguity in universities and K-12 scools and the limits of contemporary leadership theory", The Leadership Quarterly, 12, 2001.

Blase, J., "Principals' instructional leadership and teacher development: Teachers' perspectives", Educational Administration Quarterly, 35 (3), 1999.

Bogler, R., "The influence of leadership style on teacher job satisfaction", Educational Administration Quarterly, 37 (5), 2001.

Bozdoğan, K., "İlköğretim okullarında görev yapan öğretmenlerin algılar1na göre; okul müdürlerinin liderlik davranışlarının okulun öğrenme ikliminin karşılaştırılması", (Yayımlanmamış Yüksek Lisans Tezi), Niğde Üniversitesi Sosyal Bilimleri Enstitüsü, Niğde, 2010.

Buluç, B., "İlköğretim okullarında bürokratik okul yapısı ile okul müdürlerinin liderlik stilleri arasındaki ilişki”, Eğitim ve Bilim (Education and Science), 34 (152), 2009.

, "Sınıf öğretmenlerinin algılarına göre okul müdürlerinin liderlik stilleri ile örgütsel bağlılık arasındaki ilişki”, Kuram ve Uygulamada Ĕ̆gitim Yönetimi (Educational Administration: Theory and Practice), 15 (57), 2009.

Burns, J. M., Leadership, New York, Harper and Row, Publishers, Inc, 1978.

Bycio, P.-Hackett, R. D.- Allen, J. S., "Further assessments of Bass's (1985) conceptualization of transactional and transformational leadership", Journal of Applied Psychology, 80 (4), 1995. 
Can, N., Öğretmen liderliği, 3. bs., Ankara, Pegem A. Yayınları, 2013.

Celep, C., Dönüşümsel liderlik, Ankara, Anı Yayınları, 2004.

Cemaloğlu, N., "Okul yöneticilerinin liderlik stilleri ile yıldırma arasındaki ilişki”, Hacettepe Üniversitesi Eğitim Fakültesi Dergisi (H. U. Journal of Education), 33, 2007.

, "Okul yöneticilerinin liderlik stillerinin farklı değişkenler açısından incelenmesi”, Türk Ĕgitim Bilimleri Dergisi, 5 (1), 2007.

Cerit, Y., "İlköğretim okulu müdürlerinin hizmet yönelimli liderlik rollerini gerçekleştirme düzeyleri”, Hacettepe Üniversitesi Eğitim Fakültesi Dergisi (H. U. Journal of Education), 33, 2007.

, "İlköğretim okulu müdürlerinin hizmet yönelimli liderlik davranışlarının öğretmenlerin tükenmişliklerine etkisi”, Kuram ve Uygulamada Ĕ̈itim Yönetimi (Educational Administration: Theory and Practice), 56, 2008.

Ceylan, A.-Keskin, H.-Eren, Ş., "Dönüşümcü ve etkileşimci liderlik ile örgütsel bağl1lık arasındaki ilişkilere yönelik bir araştırma", Yönetim / İstanbul Üniversitesi Işsletme Fakültesi Işsletme İktisadi Enstitüsü Dergisi, 16 (51), 2005.

Clement, R. W., "Culture, leadership and power: The keys to organizational change", Business Horizons, 37, January-February, 1994.

Coad, A. F.-Berry, A. J., "Transformational leadership and learning Orientation", The Leadership and Organization Development Journal, 19 (3), 1998.

Çağlar, İ., "İktisadi ve idari bilimler fakültesi öğrencileri ile mühendislik fakültesi öğrencilerinin liderlik tarzına ilişkin eğilimlerinin karşılaştırmalı analizi ve Çorum örneği”, Ticaret ve Turizm Eğitim Fakültesi Dergisi, 2, 2004.

Çelik, S.-Eryılmaz, F., "Öğretmen algılarına göre endüstri meslek lisesi müdürlerinin dönüşümcü liderlik düzeyleri (Ankara ili örneği)", Politeknik Dergisi, 9 (4), 2006.

Çelik, V., Eğitimsel liderlik, 7. bs., Ankara, Pegem A. Yayınları, 2013.

Çetin, M., "İlköğretim öğretmenlerinin ve müdür yardımcılarının algılarına göre okul müdürlerinin liderlik yeterlilikleri”, (Yayımlanmamış Yüksek Lisans Tezi), Yeditepe Üniversitesi Sosyal Bilimler Enstitüsü, İstanbul, 2009.

Çiçek, G. E., "İlköğretim okulu öğretmenlerinin müdürlerinin liderlik rollerine ilişkin algılarının bazı değişkenlere göre incelenmesi”, (Yayımlanmamış Yüksek Lisans Tezi), Ege Üniversitesi Sosyal Bilimler Enstitüsü, İzmir, 2010.

Decker, S. R., "The relationship among principal power tactic usage, leadership style and school climate in selected Iowa elementary schools", (Unpublished doctoral dissertation), University of Northern Iowa, Cedar Falls, 1989. 
Deluga, R. J., "The effects of transformational, transactional and Laissez Faire leadership characteristics on subordinate influencing behavior", Basic and Applied Social Psychology, 11 (2), 1990.

DiPaola, M. F.- Hoy, W. K., "Organizational citizenship of faculty and achievement of high school students", The High School Journal, 88 (3), 2005.

DiPaola, M.-Tschannen Moran, M., "Organizational citizenship behavior in schools and its relationship to school climate", Journal of School Leadership, 11 (5), 2001.

Drucker, P. F., "The coming of the new organization", Harvard Business Review, 28, January-February, 1988.

, Kendini yönetmek: esaslar: Harvard Business Review'den en kalıcı yönetim fikirleri, çev. M. İnan İstanbul, Optimist Yayınları, 2012.

Eagly, A. H.-Johannesen Schmidt, M. C.-Van Engen, M. L., “Transformational, transactional and Laissez-Faire leadership styles: A meta-analysis comparing women and men", Psychological Bulletin, 129 (4), 2003.

Eraslan, L., "Liderlik olgusunun tarihsel evrimi, temel kavramlar ve yeni liderlik paradigmasının analizi”, Milli Ë̆itim Dergisi, 162, 2004.

Erdem, O.-Dikici, A. M., "Liderlik ve kurum kültürü etkileşimi”, Elektronik Sosyal Bilimler Dergisi, 8 (29), 2009.

Eren, E., Örgütsel davranış ve yönetim psikolojisi, 14. bs., İstanbul, Beta Yayınlar1, 2012.

Ergin, C.-Kozan, M. K., "Çalışanların temel değerleri, dönüşümsel ve etkileşimsel liderlerin çekiciliği”, Türk Psikoloji Dergisi, 19 (54), 2004.

Geijsel, F.-Sleegers, P.-Leithwood, K.-Jantzi, D., "Transformational leadership effects on teachers' commitment and effort toward school reform", Journal of Educational Administration, 41 (3), 2002.

Goleman, D., "Leadership that gets results", Harvard Business Review, 3-4, 2000.

Greenfield, Jr. W. D., "Moral leadership in schools", Journal of Educational Administration, 42 (2), 2004.

Güllü, E., "Sınıf öğretmenlerinin algılarına göre okul yöneticilerinin liderlik stilleri ile öğretmenlerin iş doyum düzeyleri arasındaki ilişki", (Yayımlanmamış Yüksek Lisans Tezi), Gazi Üniversitesi Eğitim Bilimleri Enstitüsü, Ankara, 2009.

Gültekin, C., "Okul yöneticilerinin liderlik stillerinin okul iklimi üzerine etkisi”, (Yayımlanmamış Yüksek Lisans Tezi), Maltepe Üniversitesi Sosyal Bilimler Enstitüsü, İstanbul, 2012. 
Güney, S., Liderlik, Ankara, Nobel Yayınları, 2012.

Herndon, B. C., "An analysis of the relationships between servant leadership, school culture, and student achievement", (Unpublished doctoral dissertation), University of Missouri, Columbia, 2007.

Hipp, K. A., "Documenting the effects of transformational leadership behavior on teacher efficacy", Paper presented at the annual meeting of the American Educational Research Association, Chicago, 1997.

Hodgetts, R. M., Yönetim: Teori, süreç ve uygulama, çev. C. Çetin, E. Can Mutlu, İstanbul, Der Yayınları, 1997.

Howell, J. M.-Avolio, B. J., "Transformational leadership, transactional leadership, locus of control, and support for innovation: Key predictors of consolidated-business-unit performance", Journal of Applied Psychology, 78 (6), 1993.

Hoy, W. K.-Miskel C. G., Ĕgitim yönetimi: Teori, araştırma ve uygulama, çev. S. Turan, Ankara, Nobel Yayınları, 2010.

Hoy, W. K.-Tarter, C. J., "Organizational justice in schools: No justice without trust", International Journal of Educational Management, 18 (4), 2004.

Koçel, T., İsletme yöneticiliği, İstanbul, Beta Yayınları, 2013.

Koh, W. L.-Steers, R. M.-Terborg, J. R., "The effects of transformational leadership on teacher attitudes and student performance in Singapore", Journal of Organizational Behavior, 16 (4), 1995.

Korkmaz, M., "Duyguların ve liderlik stillerinin öğretmenlerin performans1 üzerinde etkisi”, Kuram ve Uygulamada Ĕ̈itim Yönetimi (Educational Administration: Theory and Practice), 43, 2005.

, "Liderlik uygulamalarının içsel okul değişkenleri ile öğrenci çıktı değişkenlerine etkisi”, Kuram ve Uygulamada Eğitim Yönetimi (Educational Administration: Theory and Practice), 48, 2006.

, "Okul müdürlerinin liderlik stilleri ile öğrenen örgüt özellikleri arasında ilişki üzerine nicel bir araştırma”, Kuram ve Uygulamada Eğitim Yönetimi (Educational Administration: Theory and Practice), 53, 2008.

Koşar, S.-Çalık, T., "Okul yöneticilerinin yönetimde gücü kullanma stilleri ile örgüt kültürü arasındaki ilişki", Kuram ve Uygulamada Eğitim Yönetimi (Educational Administration: Theory and Practice), 17 (4), 2011.

Kotter, J. P., The leadership factor, New York, The Free Press, a Division of Macmillan, Inc, 1988.

(11), 2001.

, "What leaders really do?", Harvard Business Review, 79 
Kul, M., "Okul yöneticilerinin liderlik stilleri ile beden eğitimi öğretmenlerinin yıldırma (mobbing) yaşama düzeyleri, örgütsel bağlılıkları ve iş doyumu arasındaki ilişki”, (Yayımlanmamış Doktora Tezi), Gazi Üniversitesi Eğitim Bilimleri Enstitüsü, Ankara, 2010.

Lambert, L., "How to build leadership capacity", Educational Leadership Alexandria, VA: ASCD, April, 1998.

Larsen, T. J., "Identification of instructional leadership behaviors and the impact of their implementatin on academic achievement", (Unpublished doctoral dissertation), University of Colorado Boulder, Boulder, 1984.

, "Identification of instructional leadership behaviors and the impact of their implementatin on academic achievement", (Unpublished doctoral dissertation), University of Colorado Boulder, Boulder, 1985.

Leithwood, K., "The move toward transformational leadership", Educational Leadership, 49 (5), 1992.

Leithwood, K.-Jantzi, D., "Transformational school leadership for large-scale reform: Effects on students, teachers, and their classroom practices", School Effectiveness and School Improvement, 17 (2), 2006.

Leithwood, K.-Menzies, T-Jantzi, D.-Leithwood, J., "School restructuring, transformational leadership and the amelioration of teacher burnout", Anxiety, Stress and Coping: An International Journal, 9 (3), 1996.

Lord, R. G.-Brown, D. J., "Leadership, values and subordinate self-concepts", The Leadership Quarterly, 12, 2001.

Lunenburg, F. C.-Ornstein A. C., Eğitim yönetimi, çev. G. Arastaman, Ankara, Nobel Yayınları, 2013.

MacKenzie, S. B.-Podsakoff, P. M.-Rich, G. A., "Transformational and transactional leadership and salesperson performance", Journal of the Academy of Marketing Science, 29 (2), 2001.

Maxwell, J. C., Liderlik nitelikleri, çev. A. Pınarbaşı, İstanbul, Beyaz Yayınlar1, 2012.

Miller, B. P., "Leadership, organizational culture, and managing change: A case study of North Carolina's Johnston Community College", (Unpublished doctoral dissertation), North Carolina State University, Raleigh, 2001.

O'Sullivan, F., "Learning organisations-reengineering school for life long learning", School Leadership and Management: Formerly School Organisation, 17 (2), 1997.

Oğuz, E., "Öğretmenlerin örgütsel vatandaşlık davranışları ile yöneticilerin 
liderlik stilleri arasındaki ilişki”, Kuram ve Uygulamada Eğitim Yönetimi (Educational Administration: Theory and Practice), 17 (3), 2011.

Okçu, V., "Okul yöneticilerinin liderlik stilleriyle öğretmenlerin örgütsel bağlılıkları ve yıldırma yaşama düzeyleri arasındaki ilişkinin incelenmesi”, (Yayımlanmamış Doktora Tezi), Gazi Üniversitesi Eğitim Bilimleri Enstitüsü, Ankara, 2011.

Oran, N., "İlköğretim ve Ortaöğretim okul yöneticilerinin dönüşümsel liderlik özelliklerine ilişkin öğretmenlerin alg1 ve beklentileri”, (Yayımlanmamış Yüksek Lisans Tezi), Trakya Üniversitesi Sosyal Bilimler Enstitüsü, Edirne, 2002.

Owen, H.-Hodgson, V.-Gazzard N., Liderlik elkitabı, çev. M. Çelik, İstanbul, Optimist Yayınları, 2011.

Özaralli, N., "Effects of transformational leadership on empowerment and team effectiveness", The Leadership and Organization Development Journal, 24 (6), 2003.

Pillai, R.-Schriesheim, C. A.-Williams, E. S., "Fairness perceptions and trust as mediators for transformational and transactional leadership: A two-sample study", Journal of Management, 25 (6), 1999.

Pounder, D. G.-Ogawa R. T.-Adams, E. A., "Leadership as an organization - wide phenomena: Its impact on school performance", Educational Administration Ouarterly, 31 (4), 1995.

Reeves, T. L., "Principal leadership and the development of organizational culture in a new school", (Unpublished doctoral dissertation), The University of North Carolina, Chapel Hill, 2006.

Robbins, S. P.-Decenzo, D. A.-Coulter, M., Yönetimin esaslarl, çev. A. Öğüt, Ankara, Nobel Yayınları, 2013.

Robbins, S. P.-Judge, T. A., Örgütsel davranış, çev. İ. Erdem, 14. bs., Ankara, Nobel Yayınları, 2012.

Şahin, S., "Okul müdürlerinin liderlik stilleriyle, okul kültürü arasındaki ilişkiler”, Yayımlanmamış Doktora Tezi, Dokuz Eylül Üniversitesi Eğitim Bilimleri Enstitüsü, İzmir, 2003.

,"İlköğretim okulu müdürlerinin dönüşümcü ve sürdürümcü liderlik stilleri (İzmir İli Örneği)”, Ĕgitim ve Bilim, 30 (135), 2005.

Silins, H.-Mulford, B., "Schools as learning organisations-effects on teacher leadership and student outcomes", Schools Effectiveness and Scholl Improvement, 15 (3-4), 2004.

Silins, H.-Mulford, B.-Zarins, S., "Leadership for organisational learning and 
student outcomes - The LOLSO Project", Paper presented at the annual meeting of the American Educational Research Association, Montreal, April, 1999.

Silins, H.-Zarins, S.-Mulford, B., "What characteristics and processes define a school as a learning organisation? Is this a useful concept to aplly to schools?", International Education Journal, 3 (1), 2002.

Şişman, M., Öğretim liderliği, 4. bs., Ankara, Pegem A. Yayınları, 2012.

Tahaoğlu, F., "İlköğretim okulu müdürlerinin liderlik rollerinin örgüt iklimine etkisi”, (Yayımlanmamış Yüksek Lisans Tezi), Gaziantep Üniversitesi Sosyal Bilimler Enstitüsü, Gaziantep, 2007.

Tahaoğlu, F.-Gedikoğlu, T., "İlköğretim okulu müdürlerinin liderlik roller", Kuram ve Uygulamada Eğitim Yönetimi (Educational Administration: Theory and Practice), 15 (58), 2009.

Temen, B., Örgütte Kişisel Gelişim, ed. A. E. Aslan, Ankara, Nobel Yayınları, 2002.

Terzi, A. R.-Yılmaz, K., "İlköğretim okulu müdürlerinin yöneticilik davranışlarının öğretmenlerin örgütsel bağlılığına etkisi”, Milli Eğitim Dergisi, 2005 .

Turan, S.-Şişman M., Sınıf yönetimi, 7. bs., Ankara, Öğreti Yayınları, 2010.

Yıldırım, C., "Okul müdürlerinin liderlik stillerinin örgütsel sağl1k üzerindeki etkisi”, (Yayımlanmamış Yüksek Lisans Tezi), Gazi Üniversitesi Sosyal Bilimler Enstitüsü, Ankara, 2006.

Yılmaz, K., "Okul yöneticilerinin destekleyici liderlik davranışları ile okullardaki güven arasındaki ilişki konusunda ilköğretim okulu öğretmenlerinin görüşleri”, Inönü Üniversitesi Eğitim Fakültesi Dergisi, 2004.

Yukl, G., "Managerial leadership: A review of theory and research", Journal of Management, 15 (2), 1989.

, "An evaluation of conceptual weaknesses in transformational and charismatic leadership theories", The Leadership Quarterly, 10 (2), 1999.

tion, Inc. 2008.

, Leadership in organizations, New Jersey, Pearson Educa-

Zaleznik, A., "Manegers and Leaders are They Different?", Harvard Business Review: Inside the mind of the leader, January 2004, 1977-2004. 